\title{
Perception of airway narrowing in a general population sample
}

\author{
C.M. Salome*, W. Xuan**, E.J. Gray*, E. Belooussova**, J.K. Peat*
}

Perception of airway narrowing in a general population sample. C.M. Salome, W.Xuan, E.J. Gray, E. Belooussova, J.K. Peat. @ERS Journals Ltd 1997.

ABSTRACT: In epidemiological studies, defining asthma as the presence of airway hyperresponsiveness (AHR) plus recent symptoms leaves two groups of subjects whose clinical significance is unclear: those with asymptomatic AHR, and those with symptoms only. The aim of the study was to determine whether subjects with symptoms only differ from the normal and asthmatic groups in the perception of airway obstruction.

Six hundred and ninety seven adults completed a questionnaire of symptoms and underwent bronchial challenge with histamine to induce airway obstruction. Recent symptoms included wheeze and morning chest tightness in the last 12 months. AHR was defined as a provoking dose of histamine causing $\geq 20 \%$ fall in forced expiratory volume in one second $($ PD20FEV1) $<3.9 \mu \mathrm{mol}$. At the end of the challenge test, subjects who felt wheezy or tight in the chest marked a value from 0 to 10 on a modified Borg scale, to describe the severity of the sensation.

Subjects with asymptomatic AHR did not differ significantly from subjects with AHR plus recent symptoms (current asthma) either in the mean fall in FEV1 or in the median Borg score. In subjects with symptoms only, the mean Borg score was not significantly different from that of the asthmatic subjects, although mean fall in FEV1 differed significantly $(\mathrm{p}<0.0001)$. In subjects with symptoms only, chest tightness correlated significantly with the fall in forced vital capacity (FVC) $(p=$ 0.011), but not with the fall in FEV1.

Subjects with asymptomatic airways hyperresponsiveness were not poor perceivers of airway narrowing, but may underreport their symptoms. Subjects with symptoms only may have enhanced perception of small changes in lung function, particularly in forced vital capacity.

Eur Respir J 1997; 10: 1052-1058.
*Dept of Medicine, University of Sydney, Sydney, Australia. **Institute of Respiratory Medicine, Royal Prince Alfred Hospital, Sydney, Australia.

\section{Correspondence: C.M. Salome}

Dept of Medicine,

University of Sydney

NSW 2006

Australia

Keywords: Airway hyperresponsiveness perception symptoms

Received: July 171996

Accepted after revision January 151997
Asthma is characterized by variable airway narrowing, which is usually indicated clinically as the presence of episodic wheeze or chest tightness. There have been many epidemiological studies of the prevalence of asthma using questionnaires which ask about the occurrence and frequency of these symptoms [1]. The problem with using symptom-based questionnaires is that people vary in their perception of airway narrowing, so that for any given fall in lung function there is a wide range of perceived chest tightness [2]. Thus, for some subjects, sensations of wheeze or chest tightness may be associated with changes in lung function that are of little clinical relevance or, alternatively, marked changes in lung function may not be perceived at all.

For epidemiological studies in adults and children, we define current asthma as the presence both of airway hyperresponsiveness (AHR) and recent symptoms [3-6]. In children, this definition distinguishes a group with ongoing, clinically relevant airway disease [4, 7]. However, AHR and symptoms can occur independently and, in any population, there are significant numbers of subjects with asymptomatic AHR, and subjects with symptoms without evidence of AHR. Whilst there are a number of alternative explanations, it is possible that the presence or absence of reported symptoms in these subjects is due to differences in their ability to perceive changes in lung function. BRAND et al. [8] suggest that subjects with asymptomatic AHR do not report symptoms because they are poor perceivers of airway narrowing. However, there have been no studies of perception of symptoms in subjects with a history of wheeze or chest tightness, without AHR.

The aim of this study was to determine whether adults from a general population sample, classified according to airway responsiveness and recent symptoms, differ in their perception of airway narrowing induced by bronchial provocation with histamine. In particular, we wished to examine the hypothesis that subjects with asymptomatic AHR are poor perceivers, while those with symptoms, but no AHR, are hyperperceivers of the sensation of chest tightness or wheeze.

\section{Methods}

\section{Population}

The study was conducted in Wagga Wagga, an inland rural town in southern New South Wales. The methods of population selection and the characteristics of the 
population have been reported in detail previously [6]. In July 1992, a large random sample of 8-11 year old children attending schools in the area were recruited for a separate study of asthma prevalence. In October 1992, a letter was sent to the home address of the adults living in the same homes as these children, inviting them to participate in the current study. All adults in the household were asked to complete a questionnaire and then attend a location in the town centre for lung function and allergy tests. Follow-up phone calls were made to arrange appointments. A telephone survey of a random selection of 305 refusers and nonattenders showed that $4 \%$ had used an asthma medication in the last month, compared to $8 \%$ of attenders $(\mathrm{p}<0.05)$. Among the attenders, there were more females than males $(\mathrm{p}<0.001)$. These differences suggest that females and subjects with recent asthma were more likely to attend.

\section{Questionnaire}

The questionnaire was a shortened version of the International Union Against Tuberculosis and Lung Disease (IUATLD) questionnaire [9], and comprised questions of recent and past respiratory symptoms, including occupational symptoms, family history, diagnosed asthma and medication use, and hospital and doctor attendances. Subjects who reported wheeze, wheeze following exercise, chest tightness on waking, or shortness of breath coming on at rest, which had occurred in the previous 12 months, were classified as having "recent symptoms".

\section{Histamine challenge}

A bronchial challenge test with histamine was administered to all subjects with baseline forced expiratory volume in one second (FEV1) $\geq 60 \%$ predicted, using the rapid method [10]. Lung function was recorded by dry rolling-seal spirometers (Mijnhardt BV, Bunnick, Holland) connected to IBM-PC computers running Scientific and Medical software for immediate data acquisition. Forced expiratory manoeuvres were repeated until two readings of FEV1 and forced vital capacity (FVC) within $100 \mathrm{~mL}$ were obtained, the largest of which was used in analyses. Values for FEV1 and FVC were recorded as a percentage of the predicted values of KNUDSON et al. [11]. Subjects who had taken short-acting $\beta$-agonist or anticholinergic aerosols within $6 \mathrm{~h}$ of presenting were asked to withhold medication before returning for later testing. Long-acting $\beta$-agonist aerosols were not available in Australia at the time of this study. Histamine diphosphate (BDH, UK) was administered using DeVilbiss No. 45 handheld nebulizers (DeVilbiss Co., Somerset, PA, USA), in doubling doses from 0.03-3.9 $\mu \mathrm{mol}$. The test was stopped if the FEV1 fell by $20 \%$ or more. Salbutamol aerosol was administered to aid recovery when necessary.

Subjects in whom a $\leq 3.9 \mu \mathrm{mol}$ dose of histamine provoked a $20 \%$ fall in FEV1 (PD20FEV1 $\leq 3.9 \mu \mathrm{mol}$ ) were classified as having AHR. Dose-response ratio (DRR) was calculated for all subjects as the percentage fall in FEV1 at the last dose, divided by the total dose administered [12]. Because many subjects had an FEV1 which remained stable or improved slightly during bronchial challenge, and thus gave a zero or negative value, a constant of 3 was added to all DRR values to obtain a positive value for logarithmic conversion $[5,13]$, so that they are indicated by the units $\%$ fall $\cdot \mu \mathrm{mol}^{-1}+3$.

Four subjects who presented with FEV $1<60 \%$ pred did not undergo histamine challenge, and their data are not included in the present report.

\section{Borg scores}

As soon as the bronchial challenge test was completed, the operator who had carried out the test asked each subject a standard question: "Did you feel wheezy or tight in the chest during the test?" If the subject answered yes, they were asked a second question: "Have you felt like that before?" Subjects were then asked to describe the severity of the sensation they experienced during the challenge by marking a value on a modified Borg scale [2]. The modified Borg scale extends from 0 to 10 , with 0 marked "Not at all" and 10 marked "Extremely severe", and simple descriptors, such as "Slight", "Moderate" or "Very severe" at intervening numbers. Specific questions about wheeze or chest tightness were asked in order to exclude symptoms of upper airway or throat irritation.

\section{Allergic sensitization}

Sensitization to common allergens was measured by the reaction to a skin-prick test to the forearm [14]. The eight allergens tested were: house dust; house dust mites (Dermatophagoides pteronyssinus and D. farinae); cat dander; ryegrass; plantain; Alternaria tenuis; and cockroach. Histamine and glycerol were used as positive and negative controls. After $15 \mathrm{~min}$, wheal size was recorded as the long axis and its perpendicular; mean wheal size was used in analyses. A reaction was regarded as positive if the wheal size was $\geq 4 \mathrm{~mm}$. Subjects were considered atopic if they had a positive reaction to any of the allergens tested.

\section{Definitions}

On the basis of data from the questionnaire and bronchial challenge, subjects were classified into four groups: 1) "Normal", no AHR and no symptoms in the last 12 months; 2) "Symptoms only", no AHR, but symptoms in the last 12 months; 3 ) "Asymptomatic AHR", PD20FEV1 $<3.9 \mu \mathrm{mol}$, no symptoms in the last 12 months; 4) "Current Asthma", PD20FEV1 $<3.9 \mu \mathrm{mol}$, symptoms in the last 12 months. For the purposes of this classification, symptoms included wheeze, wheeze following exercise, chest tightness on waking, or shortness of breath coming on at rest.

\section{Statistical analysis}

Data were analysed using the Statistical Analysis System (SAS) software package (SAS Institute Inc., Cary, NC, USA). Geometric mean values are reported for 
DRR values, which were transformed to base 10 logarithms before analysis. Mean values are given with the $95 \%$ confidence intervals $(95 \% \mathrm{CI})$. Confidence intervals for proportions close to the extreme were calculated using the formula of FLEISS [15], in order to avoid confidence intervals outside the possible range. Median values, and the interquartile range, are given for the Borg scores. Chi-squared analyses were used to determine associations between categorical variables, and unpaired ttests were used for continuous, normally-distributed variables. Spearman's rank correlation coefficients were calculated to examine the association between Borg score and the lung function variables. Comparisons of Borg scores between groups were made using the KruskalWallis test for multiple comparisons and the Wilcoxon signed ranks test for two group comparisons. Analysis of variance (ANOVA) using Duncan's post-hoc test was used to assess differences in lung function between the four groups. A p-value of less than 0.05 was considered significant.

Logistic regression was used to determine the factors associated with experiencing wheeze or chest tightness during the challenge test. Spearman's correlation coefficients were used to determine which variables were associated with magnitude of the Borg score in subjects who experienced chest tightness and wheezing during the challenge. A stepwise procedure, using partial correlation coefficients, was used to determine which variables were independently associated with the Borg score.

\section{Results}

It was estimated that the group of adults who attended for testing comprised $62 \%$ of the sample base. Of the 697 adults (aged 18-73 yrs) who underwent challenge testing with histamine, $74 \%$ were classified as normal (having neither AHR nor recent symptoms), $6 \%$ had current asthma (with both AHR and recent symptoms), $18 \%$ had symptoms only, and 3\% had asymptomatic AHR. Table 1 shows the characteristics of the four groups. They did not differ significantly in mean age, in the proportion of current and ex-smokers, or in gender ratio, although males were underrepresented in all groups. Mean DRR differed significantly between all groups, and both atopy and abnormal baseline lung function, defined as FEV1/FVC ratio $<75 \%$, were more common in the two groups with AHR.

The percentage of subjects in each group who experienced symptoms of wheeze or chest tightness during the bronchial challenge test is shown in table 2. Most of the subjects with current asthma experienced symptoms, whilst relatively few of the normal subjects felt wheeze or chest tightness. Of the subjects with asymptomatic AHR, $86 \%$ felt wheeze or chest tightness during the challenge, and two thirds of these had experienced these feelings before. More than half of the "Symptoms only" group experienced wheeze or chest tightness during challenge, and $92 \%$ of these had felt the sensation before.

Table 1. - Characteristics of subject groups classified on the basis of symptom history, the questionnaire, and AHR to histamine

\begin{tabular}{|c|c|c|c|c|c|c|c|c|}
\hline & \multicolumn{2}{|c|}{ Normal } & \multicolumn{2}{|c|}{ Symptoms only } & \multicolumn{2}{|c|}{ Asymptomatic AHR } & \multicolumn{2}{|c|}{ Asthma } \\
\hline Subjects $\mathrm{n}$ & 512 & & 124 & & 22 & & 39 & \\
\hline Male \% & 44 & & 40 & & 40 & & 46 & \\
\hline Mean age yrs & 38 & $(38-39)$ & 38 & $(37-39)$ & 40 & $(36-44)$ & 37 & $(35-38)$ \\
\hline Atopic \% & 43 & $(39-47)$ & 59 & $(50-68)$ & 86 & $(64-96)$ & 92 & (78-98) \\
\hline Current smokers \% & 18 & $(14-21)$ & 25 & $(17-33)$ & 18 & $(2-34)$ & 26 & $(12-39)$ \\
\hline Ex-smokers \% & 28 & $(24-32)$ & 25 & $(17-33)$ & 27 & $(9-46)$ & 23 & $(10-36)$ \\
\hline FEV1 \% pred & 102 & $(101-103)$ & 98 & $(95-101)$ & 97 & $(92-101)$ & 92 & $(87-96)$ \\
\hline FVC \% pred & 98 & $(98-100)$ & 96 & (94-99) & 98 & $(95-102)$ & 97 & $(92-102)$ \\
\hline Abnormal lung function $\%$ & 3 & $(1-4)$ & 10 & $(5-16)$ & 27 & $(9-46)$ & 36 & $(21-51)$ \\
\hline Mean DRR $\%$ fall $\cdot \mu \mathrm{mol}^{-1}+3$ & 3.9 & $(3.8-4.0)$ & 4.7 & $(4.5-5.0)$ & 11.6 & $(9.9-13.7)$ & 30.2 & $(20.0-45.8)$ \\
\hline
\end{tabular}

Values are either percentage of subject group or means, with $95 \%$ confidence intervals in parentheses. Abnormal lung function and dose response ratio (DRR) are defined in the text. AHR: airway hyperresponsiveness; FEV1: forced expiratory volume in one second; FVC: forced vital capacity; \% pred: percentage of predicted value.

Table 2. - Number of subjects who felt symptoms of wheeze or chest tightness during bronchial challenge with histamine, the percentage who had felt these symptoms before, and the mean falls $(\Delta)$ in lung function during bronchial challenge in those subjects

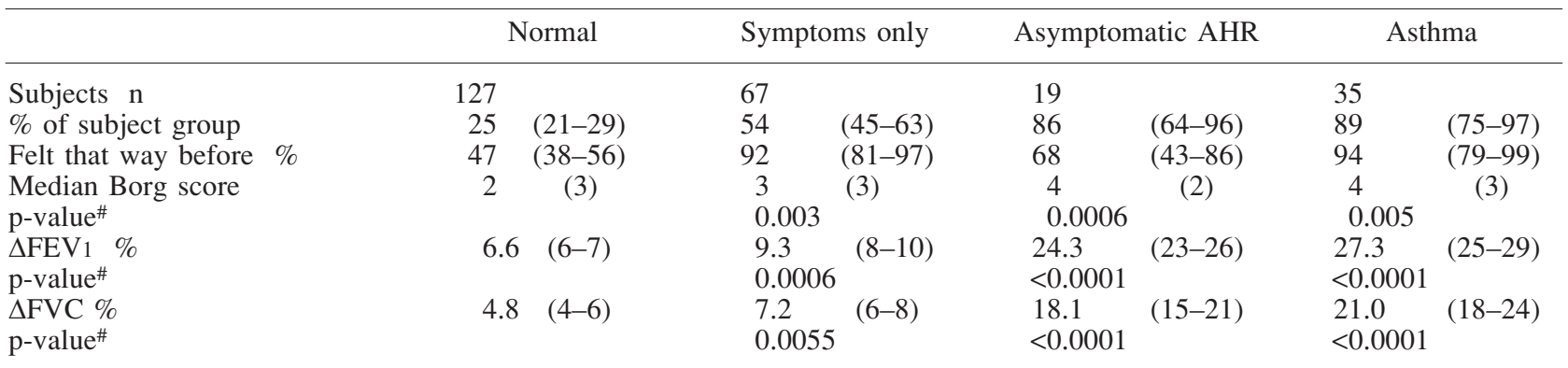

Values in parentheses are 95\% confidence intervals (95\% CI), with the exception of the severity scores for wheeze or chest tightness which are shown as medians and interquartile range (IQR) in parenthesis. \#: compared with the normal group. For definitions see legend to table 1 . 
Atopy, AHR, recent wheeze, current use of asthma medication, and smoking history (current or past smoking) were significant risk factors for the occurrence of wheeze or tightness during the challenge. The odds ratios, adjusted for each of these factors, are shown in figure 1 . In the Normal group, the occurrence of wheeze or tightness during the challenge was significantly associated both with atopy (Chi-squared $=9.62 ; \mathrm{p}<0.01)$ and with smoking history (Chi-squared 13.24; $\mathrm{p}<0.001$ ). These associations were not significant in the group with symptoms only.

The median Borg scores and the mean falls in FEV1 and FVC in those subjects who experienced symptoms during the challenge are shown in table 2. In the Normal group, the median Borg score, indicating the severity of wheeze or chest tightness during the challenge, differed significantly from that in the other three groups $(\mathrm{p}=$ 0.0008 ). Subjects with asymptomatic AHR did not differ significantly from subjects with current asthma either in the mean fall in FEV1 or in the median Borg score at the end of the challenge. In subjects with symptoms only, the median Borg score was not significantly different from that of the asthmatic subjects $(p=0.65)$, despite a large difference in the mean fall in FEV1 (9 vs $27 \%$; $\mathrm{p}<0.0001$ ).

Normal subjects and those with symptoms only, by definition, had falls in FEV1 during the bronchial challenge test which were less than $20 \%$. However, many of these subjects experienced wheeze or chest tightness during the test. Those who reported such sensations had significantly greater falls in FEV1 and FVC than those who did not feel wheeze or chest tightness (table 3 ).

Borg score was significantly correlated with change in FEV1 (Spearmans $\rho=0.33 ; p<0.0001)$ and FVC $(\rho=0.35$; $\mathrm{p}<0.0001)$. Despite this significant correlation, fall in FEV1 explained only $8 \%$ of the variation in Borg score, and, for any given fall in FEV1, there was a wide range of perceived severity. In the subjects with symptoms only, Borg score correlated with the fall in FVC $(\rho=0.33$; $p=0.0078)$, but not with the fall in FEV1 $(\rho=0.19 ; p=0.12)$ (fig. 2). In the other three subject groups, there were no significant correlations between Borg score and change in lung function. In the two groups with AHR, there was no significant correlation between Borg score and DRR

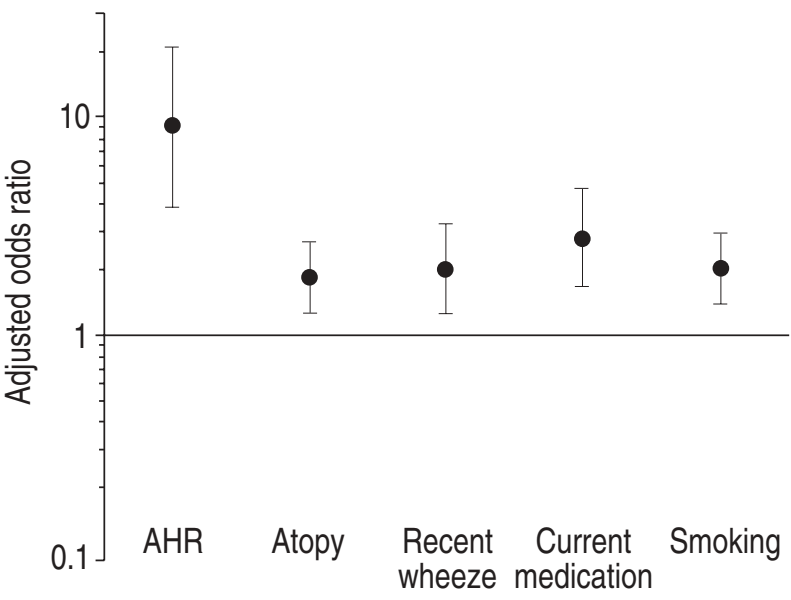

Fig. 1. - Adjusted odds ratios ( $\pm 95 \%$ confidence interval) for the significant risk factors for the occurrence of wheeze or chest tightness during bronchial challenge with histamine, in the sample of 697 adults. AHR: airway hyperresponsiveness.
Table 3. - Falls $(\Delta)$ in FEV 1 and FVC in the subjects without AHR who felt wheeze or chest tightness, and in those who did not feel wheeze or chest tightness during the challenge

\begin{tabular}{|c|c|c|c|}
\hline & $\begin{array}{l}\text { Subjects with } \\
\text { wheeze or chest } \\
\text { tightness }\end{array}$ & $\begin{array}{l}\text { Subjects without } \\
\text { wheeze or chest } \\
\text { tightness }\end{array}$ & $\mathrm{p}$-value \\
\hline \multicolumn{4}{|c|}{ Normal group } \\
\hline Subjects $\mathrm{n}$ & 127 & 385 & \\
\hline$\triangle \mathrm{FEV}_{1} \quad \%$ & $\begin{array}{c}7 \\
(6-8)\end{array}$ & $\begin{array}{c}3 \\
(3-4)\end{array}$ & $<0.0001$ \\
\hline$\Delta \mathrm{FVC} \%$ & $\begin{array}{c}5 \\
(4-6)\end{array}$ & $\begin{array}{c}2 \\
(2-3)\end{array}$ & $<0.0001$ \\
\hline \multicolumn{4}{|c|}{ Symptoms only } \\
\hline Subjects $n$ & 67 & 57 & \\
\hline$\triangle \mathrm{FEV}_{1} \quad \%$ & $\begin{array}{c}9 \\
(8-10)\end{array}$ & $\begin{array}{c}5 \\
(4-6)\end{array}$ & $<0.0001$ \\
\hline$\Delta \mathrm{FVC} \%$ & $\begin{array}{c}7 \\
(6-8)\end{array}$ & $\begin{array}{c}4 \\
(3-6)\end{array}$ & 0.0074 \\
\hline
\end{tabular}

Values are presented as means, and $95 \%$ confidence intervals in parentheses. For definitions see legend to table 1.
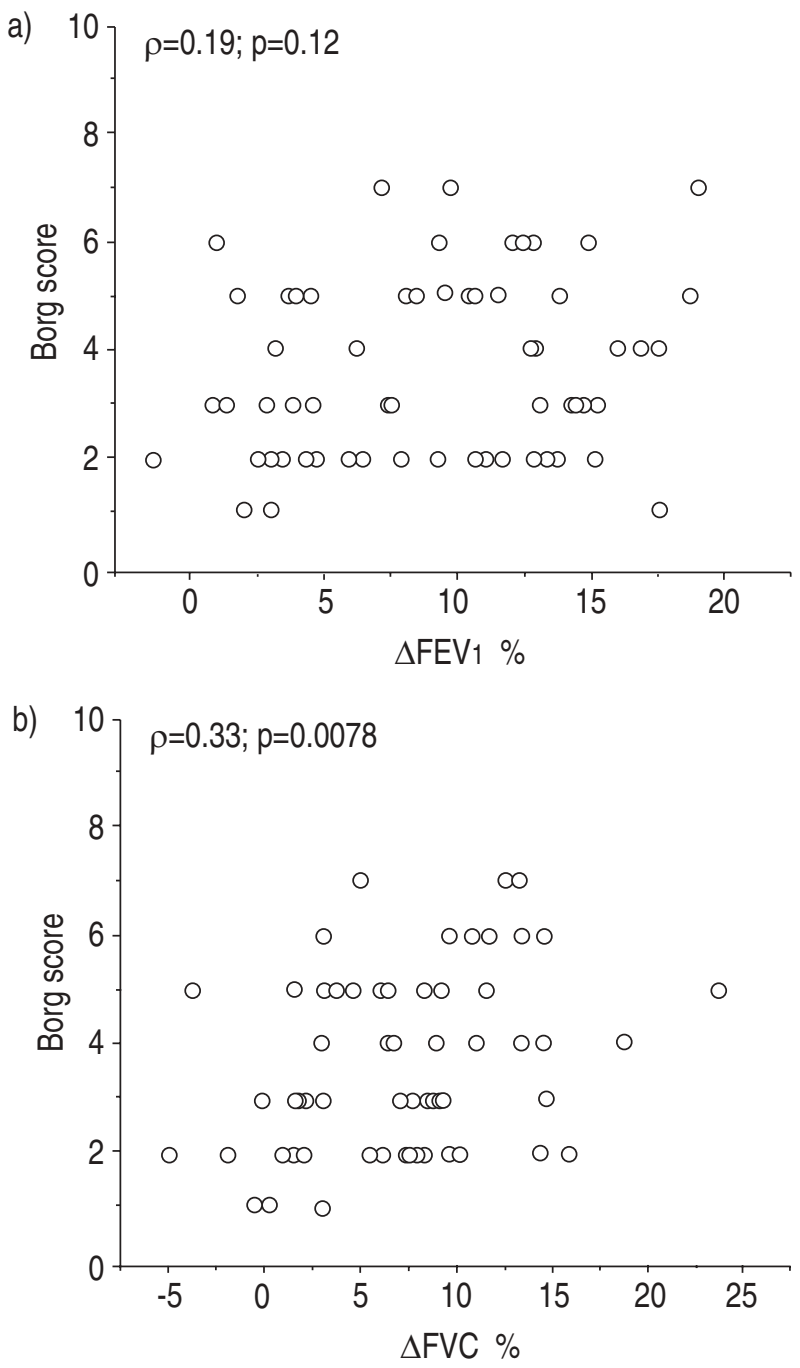

Fig. 2. - Relationship between: a) $\triangle \mathrm{FEV}_{1}$; and b) $\triangle \mathrm{FVC}$ and Borg score for wheeze or chest tightness in the 67 subjects in the "Symptoms only" group who experienced these symptoms during bronchial challenge. $\triangle F E V_{1}$ : change in forced expiratory volume in one second; $\triangle \mathrm{FVC}$ : change in forced vital capacity. 
( $\rho=0.08$ and -0.04 for the asthma and AHR only groups, respectively).

Partial correlation coefficients were used to determine which factors were independently associated with severity of wheeze and chest tightness. In the group as a whole, two factors were significantly associated with Borg score: percentage fall in FVC $(\rho=0.35 ; p=0.0001)$ and current use of asthma medication (partial $\rho=0.14$; $\mathrm{p}=0.027$ ). Once these factors were accounted for, no further variation in Borg score was associated with dose response ratio, percentage fall in FEV1, baseline FEV1, baseline FVC, baseline FEV1/FVC ratio, or age. Similar analyses using only data from the groups without AHR, that is the Normal and Symptoms only groups, produced a model which included three factors: percentage fall in FVC $(\rho=0.30 ; p=0.0001)$, current use of asthma medication (partial $\rho=0.21 ; p=0.0045$ ), and baseline FVC (partial $\rho=-0.17 ; p=0.019)$.

\section{Discussion}

This study has shown that, in this population of adults, wheeze and chest tightness induced by bronchial challenge with histamine were related to changes in FEV1 and FVC, but these changes explained only a small portion of the variation in symptom severity. Almost all of the subjects with asymptomatic AHR experienced wheeze or chest tightness during the bronchial challenge, and many recognized the sensation as one they had experienced previously. The severity of the sensation was not significantly different from that experienced by subjects with current asthma. These findings suggest that subjects with asymptomatic AHR are not poor perceivers of airway narrowing, but that they may underreport their symptoms. On the other hand, subjects with recent symptoms but no AHR to histamine appeared to have a heightened sensation of small changes in lung function induced by histamine. The severity of wheeze and chest tightness in these subjects was similar to that experienced by the asthmatic subjects, despite the fact that their change in lung function was considerably smaller than in the asthmatic subjects.

In this study, standard methods with established reliability were used to classify the subjects according to their airway responsiveness and recent symptoms. We used a well-established method for the histamine challenge [10], and a shortened version of the standard IUATLD questionnaire [9]. Asthma was defined as the presence of AHR and recent symptoms of wheeze, wheeze with exercise, chest tightness on waking, or shortness of breath coming on at rest. This definition discriminates asthma symptoms and identifies the group with the most severe impairment [4,7]. Although the response rate was low, and only just adequate for estimates of prevalence, comparisons between groups of change in lung function and of Borg scores are likely to be reliable. There was a slightly higher rate of attenders with recent asthma, increasing the numbers in the symptomatic groups, but this is unlikely to introduce any bias into the measurements of sensation or lung function change in these groups. The number of subjects in the group with asymptomatic AHR was small, and this is reflected in the larger confidence intervals for the symptom scores and change in lung function in this group. However, the sample size was sufficient to show that the measurements in this group differed significantly from the Normal group.

The modified Borg scale, used in this study to measure the severity of perceived wheeze or chest tightness, has been used in other studies of spontaneous and induced airway narrowing $[2,8,16]$. In this study, a single measurement was made at the end of challenge, when the subjects were asked to rate the severity of the sensations they experienced during the challenge test. This technique differs from that used in other studies, where Borg scores have been measured before and after challenge, allowing the association between change in lung function and change in sensation to be estimated. In the present study, we wished to exclude sensations in the upper airway or throat caused by the irritant effect of histamine, and focus on sensations in the lower airways. To do this, we avoided asking an open-ended question about any symptoms the subjects may have experienced, and asked specifically about wheeze or chest tightness, sensations which could be attributed to the lower airways.

Subjects with asymptomatic AHR had Borg scores which were not different from those of the asthmatic subjects, suggesting that they were not poor perceivers of acute airway narrowing. This finding is consistent with that of GiBSON et al. [17], who also found that children with asymptomatic AHR to methacholine experienced symptoms during the challenge. On the other hand, the present findings differ from those of BRAND et al. [8], who suggest that asymptomatic AHR is associated with reduced perception of airway narrowing. However, there are substantial differences in methodology between the present study and that of BRAND et al. [8], whose study population included subjects with much milder AHR, and who used the Borg score before and after challenge to measure change in breathlessness. The measurements were made at $\geq 10 \%$ fall in FEV1, rather than at $\geq 20 \%$ fall as in the present study, and were analysed as a dichotomous (change/no change) variable.

It is likely that many subjects with asymptomatic AHR underreport their symptoms. Two thirds of the subjects with asymptomatic AHR recognized the sensation of wheeze or chest tightness induced by the challenge as something that they had experienced previously. In the questionnaire, subjects were asked to report symptoms that had occurred within the last 12 months. It seems likely that some underreporting would occur over such a long recall period, particularly if the symptoms were mild or infrequent. The mean DRR values in the group with asymptomatic AHR were only just in the abnormal range [5], suggesting that the airway abnormality in this group is mild. In other studies, asymptomatic AHR has been associated with increased risk of symptoms at a later date $[18,19]$, and with increased peak expiratory flow (PEF) variability [17], suggesting that these subjects may have very mild or unrecognized asthma.

Alternatively, subjects with asymptomatic AHR may have a different airway pathology from that found in asthma. In the present study, one third of the group with asymptomatic AHR did not recognize the sensation of chest tightness or wheeze, and presumably had no prior experience of such symptoms. GIBSON et al. [17] also 
found that few of their children with asymptomatic AHR recognized the symptoms induced by methacholine challenge as something they had experienced previously. In children with asymptomatic AHR, the number of eosinophils in induced sputum does not differ from that in normal children [20], suggesting that airway inflammation is a not a feature of the pathology. It has been suggested that the sensation of bronchoconstriction is enhanced by the presence of airway inflammation [21], and that the absence of symptoms in subjects with asymptomatic AHR may be due to the absence of airway inflammation [17]. Airway hyperresponsiveness in the absence of airway inflammation may reflect some other abnormality of airway geometry or structure.

Subjects with asymptomatic AHR had less severe AHR than the current asthma group, and thus received a larger total dose of histamine during the challenge procedure. However, it seems unlikely that the higher doses of histamine had a direct effect on sensation in these subjects, since there was no correlation between DRR and Borg score in the hyperresponsive groups. This is consistent with the findings of BRAND et al. [8], who also found no correlation between perception scores and AHR.

Subjects with recent symptoms, but no AHR, perceived the sensation of bronchoconstriction with a similar severity to that of the asthmatic subjects, even though they had a much smaller fall in FEV1 during challenge. It is not clear if these subjects have asthma or any other significant airway problem. Almost $51 \%$ of the Symptoms only group had experienced symptoms which were severe enough to have required bronchodilator medications in the last 12 months. Current medication was a significant factor in the model predicting Borg score, suggesting that those subjects with symptoms severe enough to require treatment tended to record the highest Borg scores, independently of the magnitude of the change in lung function.

Since treatment with inhaled corticosteroids can reduce AHR in people with current symptoms [22], it could be argued that subjects with recent symptoms, but no AHR, may have lost their AHR as a result of corticosteroid therapy. However, only $14 \%$ of the Symptoms only group had taken inhaled corticosteroids in the 12 months prior to testing, suggesting that such treatment is unlikely to account for the absence of AHR in most of this group.

Alternatively, AHR may be absent in subjects with episodic, seasonal asthma, if they are tested out of season [23]. In the Symptoms only group, there were significantly more atopic subjects, and more pollen atopic subjects than in the Normal group (44 vs 23\%), suggesting that some may have been at risk of seasonal symptoms. The studies were conducted in October, spring in the southern hemisphere, when pollen levels were likely to be at their highest, and thus pollen sensitive subjects would be more likely to have AHR at this time. Atopy was a significant risk factor for the occurrence of wheeze or chest tightness during the challenge test in the group as a whole; however, there was no significant association when the Symptoms only group was considered separately.

More than half of the subjects in the Symptoms only group reported feeling chest tightness during the challenge, and almost all of these had felt this sensation before. In these subjects, the fall in FEV1 was small compared to that in the subjects with AHR, suggesting that they may be hyperperceivers of small changes in lung function. In asthmatic subjects, recent evidence suggests that breathlessness during induced obstruction is closely related to airway closure and hyperinflation. LOUGHEED et al. [16] have shown that change in inspiratory capacity explains $20.6 \%$ of variation in Borg score during challenge with methacholine and $19.4 \%$ during bronchodilation. In the present study, fall in FVC was the factor most strongly associated with Borg score. In the Symptoms only group, the severity of histamineinduced symptoms correlated with change in FVC during the challenge, but not with change in FEV1. Although the mean fall in FVC was only 7\%, these data suggest that, in this group of subjects, airway closure and hyperinflation may be a determinant of symptoms during challenge.

A small proportion of normal subjects felt chest tightness or wheeze during the challenge, but less than half of these recognized the sensation as something they had felt before. In the Normal group, those who felt chesttightness had greater falls in lung function than those who did not, and the occurrence of symptoms during the challenge was strongly associated with a history of smoking and, to a lesser extent, with atopy. In some normal subjects, smoking and atopy may enhance the response of the airways to histamine, so that these subjects are able to perceive the small changes in lung function which occur during challenge. In subjects with AHR, BRAND et al. [8] did not find any association between smoking and change in Borg score after challenge.

The definition of asthma depends, in part, on the ability of subjects to report their symptoms. In this study, we have shown that many subjects are able to perceive changes in lung function, which may be quite small. However, subjects vary widely, not only in the perceived severity of lung function changes, but also in the likelihood that such changes will be reported as symptoms. Further studies are needed to evaluate the prognostic significance of symptoms which occur in the absence of airways hyperresponsiveness, and to determine whether such symptoms are associated with airway inflammation.

Acknowledgements: The authors acknowledge the financial support of Allen and Hanburys, the National Health and Medical Research Council of Australia, the Asthma Foundation of NSW and the Community Health and Anti-Tuberculosis Association. They also thank the Wagga Wagga branch of the Asthma Foundation of NSW, for help in organizing the study, and the research assistants who helped to collect the data.

\section{References}

1. Robertson CF, Bishop J, Sennhauser FH, Mallol J. International comparison of asthma prevalence in children: Australia, Switzerland, Chile. Pediatr Pulmonol 1993; 16: 219-226.

2. Burdon JGW, Juniper EF, Killian KJ, Hargreave FE, Campbell EJM. The perception of breathlessness in asthma. Am Rev Respir Dis 1982; 126: 825-828.

3. Salome CM, Peat JK, Britton WJ, Woolcock AJ. Bronchial responsiveness in two populations of Australian 
schoolchildren. I. Relation to respiratory symptoms and diagnosed asthma. Clin Allergy 1987; 17: 271-281.

4. Toelle BG, Peat JK, Salome CM, Mellis CM, Woolcock AJ. Toward a definition of asthma for epidemiology. Am Rev Respir Dis 1992; 146: 633-637.

5. Peat JK, Salome CM, Berry G, Woolcock AJ. Relation of dose-response slope to respiratory symptoms and lung function in a population study of adults living in Busselton, Western Australia. Am Rev Respir Dis 1992; 146: 860-865.

6. Peat JK, Gray EJ, Mellis CM, Leeder SR, Woolcock AJ. Differences in airway responsiveness between children and adults living in the same environment: an epidemiological study in two regions of New South Wales. Eur Respir J 1994; 7: 1805-1813.

7. Peat JK, Toelle BG, Salome CM, Woolcock AJ. Predictive nature of bronchial responsiveness and respiratory symptoms in a one year cohort study of Sydney schoolchildren. Eur Respir J 1993; 6: 662-669.

8. Brand PLP, Rijken B, Schouten JP, Koeter GH, Weiss ST, Postma DS. Perception of airway obstruction in a random population sample. Relationship to airway hyperresponsiveness in the absence of respiratory symptoms. Am Rev Respir Dis 1992; 146: 396-401.

9. Burney P, Laitinen LA, Perdrizet S, et al. Validity and repeatability of the IUATLD (1984) Bronchial Symptoms Questionnaire: an international comparison. Eur Respir J 1989; 2: 940-945.

10. Yan K, Salome C, Woolcock A. Rapid method for the measurement of bronchial responsiveness. Thorax 1983; 38: 760-765.

11. Knudson RJ, Lebowitz MD, Holberg CJ, Burrows B. Changes in the normal maximal expiratory flow-volume curve with growth and aging. Am Rev Respir Dis 1983; 127: 725-734.

12. O'Connor G, Sparrow D, Taylor D, Segal M, Weiss S. Analysis of dose response curves to methacholine: an approach suitable for population studies. Am Rev Respir Dis 1987; 136: 1412-1417.
13. Peat JK, Salome CM, Berry G, Woolcock AJ. Relation of dose-response slope to respiratory symptoms in a population of Australian schoolchildren. Am Rev Respir Dis 1991; 144: 663-667.

14. Pepys J. Skin testing. Br J Hosp Med 1975; 14: 412-417.

15. Fleiss JL. Statistical methods for rates and proportions. 2nd ed. NY, John Wiley \& Sons Inc., 1981.

16. Lougheed MD, Lam M, Forkert L, Webb KA, O'Donnell DE. Breathlessness during acute bronchoconstriction in asthma. Am Rev Respir Dis 1993; 148: 1452-1459.

17. Gibson PG, Mattoli S, Sears MR, Dolovich J, Hargreave FE. Increased peak flow variability in children with asymptomatic hyperresponsiveness. Eur Respir J 1995; 8: $1731-1735$.

18. Jones A. Asymptomatic bronchial hyperreactivity and the development of asthma and other respiratory tract illnesses in children. Thorax 1994; 49: 757-761.

19. Carey VJ, Weiss ST, Tager IB, Leeder SR, Speizer FE. Airways responsiveness, wheeze onset, and recurrent asthma episodes in young adolescents: the East Boston childhood respiratory disease cohort. Am J Respir Crit Care Med 1996; 153: 356-361.

20. Pin I, Radford S, Kolndowicz R, et al. Airway inflammation in symptomatic and asymptomatic children with methacholine hyperresponsiveness. Eur Respir J 1993; 6: 1249-1256.

21. Sont JK, Booms P, Bel EH, Vandenbroucke JP, Sterk PJ. The severity of breathlessness during challenges with inhaled methacholine and hypertonic saline in atopic and asthmatic subjects. Am J Respir Crit Care Med 1995; 152: 38-44.

22. Du Toit JI, Salome CM, Woolcock AJ. Inhaled corticosteroids reduce the severity of bronchial hyperresponsiveness in asthma but oral theophylline does not. Am Rev Respir Dis 1987; 136: 1174-1178.

23. Boulet L-P, Cartier A, Thomson NC, Roberts RS, Dolovich J, Hargreave FE. Asthma and increases in nonallergic bronchial responsiveness from seasonal pollen exposure. J Allergy Clin Immunol 1983; 71: 399-406. 